Article

Subscriber access provided by University of East Anglia Library

\title{
Significantly enhanced thermoelectric performance of \#-In2Se3 through lithiation via chemical diffusion
}

\author{
Jiaolin Cui, Hua Peng, Zhiliang Song, Zhengliang Du, Yimin Chao, and Gang Chen
}

Chem. Mater., Just Accepted Manuscript • DOI: 10.1021/acs.chemmater.7b02467 • Publication Date (Web): 09 Aug 2017

Downloaded from http://pubs.acs.org on August 15, 2017

\section{Just Accepted}

"Just Accepted" manuscripts have been peer-reviewed and accepted for publication. They are posted online prior to technical editing, formatting for publication and author proofing. The American Chemical Society provides "Just Accepted" as a free service to the research community to expedite the dissemination of scientific material as soon as possible after acceptance. "Just Accepted" manuscripts appear in full in PDF format accompanied by an HTML abstract. "Just Accepted" manuscripts have been fully peer reviewed, but should not be considered the official version of record. They are accessible to all readers and citable by the Digital Object Identifier (DOI®). "Just Accepted" is an optional service offered to authors. Therefore, the "Just Accepted" Web site may not include all articles that will be published in the journal. After a manuscript is technically edited and formatted, it will be removed from the "Just Accepted" Web site and published as an ASAP article. Note that technical editing may introduce minor changes to the manuscript text and/or graphics which could affect content, and all legal disclaimers and ethical guidelines that apply to the journal pertain. ACS cannot be held responsible for errors or consequences arising from the use of information contained in these "Just Accepted" manuscripts. 


\section{Introduction}

Thermoelectric (TE) materials have attracted much attention in recent years that they are capable of harvesting huge amount of waste heat by converting heat into electricity. However, the conversion efficiency is still low and high performance TE materials are limited up to date. Although many compounds, such as $\mathrm{PbTe}-1,2$ $\mathrm{SnSe}-{ }^{3,4} \mathrm{Mg}_{2} \mathrm{Si}_{-}{ }^{5}$ and some other tellurides, ${ }^{6}$ present potential TE performance, it is still urgent to develop high performance and new environmentally benign TE materials for mid temperature power generation applications.

Indium selenide $\left(\mathrm{In}_{2} \mathrm{Se}_{3}\right)$ could be used as phase-change random access memory device and thermoelectric material, due to its large bandgap, ${ }^{7}$ intrinsic low thermal conductivity and high Seebeck coefficient. $^{8}$ - 10 However, there are different coexisting phases and crystal structures, such as rhombohedral / hexagonal $\alpha$ / $\beta$ phases, hexagonal $\gamma$ and $\delta$ phases, some of which, for example, $\alpha-$ and $\beta$ - phases, exist in a metastable state and are inclined to mutual transformation on heating or cooling. ${ }^{11}$ Therefore, it is difficult to synthesize single $\alpha$ - or $\beta-\mathrm{In}_{2} \mathrm{Se}_{3}$-based solid solutions. ${ }^{12,13}$ Accordingly, the $\gamma$-phase, which is stable above $520 \mathrm{C}^{\circ}{ }^{12} 625 \mathrm{C}^{\circ}$ ${ }^{14}$ or $650 \mathrm{C}^{\circ}, 15$ in terms of different experiments, might be an alternative indium selenide used for TE applications in the region of mid to high temperatures.

$\gamma-\mathrm{In}_{2} \mathrm{Se}_{3}$ behaves like an insulator with the bandgap of $1.9 \mathrm{eV} .{ }^{16}$ Unlike $\alpha-\mathrm{In}_{2} \mathrm{Se}_{3}$, it has intrinsic screw - like ordering vacancies, ${ }^{17}-19$ instead of layer-like ones. However, there are 1/3 structural 
vacancies existing along the c-axis in $\mathrm{\gamma}-\mathrm{In}_{2} \mathrm{Se}_{3}$, which accommodates cations with different sizes. It has been reported that the diffusion of cations, such as $\mathrm{Li}$ with small size, into the crystal lattice of $\mathrm{In}_{2} \mathrm{Se}_{3}$, forms metallic phase $\mathrm{Li}_{0.1} \mathrm{In}_{2} \mathrm{Se}_{3}$, enhancing the free carrier concentration by more than three orders of magnitude (from $10^{16} \mathrm{~cm}^{-3}$ to $1.5 \times 10^{19} \mathrm{~cm}^{-3}$ ). ${ }^{20}$ In addition, the impurity occupation in the cation sites could induce the shift of the Fermi level $\left(F_{\mathrm{r}}\right)$, thus engineering the band structure. ${ }^{21}$ Therefore, the impurity doping in $\gamma-\mathrm{In}_{2} \mathrm{Se}_{3}$ have a profound impact on the structure and TE performance of the host materials.

In this work, we have prepared lithiated $\gamma-\mathrm{In}_{2} \mathrm{Se}_{3}$ powders via chemical diffusion, and examined transport and TE properties from room temperature (RT) to $\sim 930 \mathrm{~K}$. The experiments reveal that doping of $\mathrm{Li}$ ion in $\mathrm{\gamma}-\mathrm{In}_{2} \mathrm{Se}_{3}$ enhances the Hall carrier concentration $\left(n_{\mathrm{H}}\right)$ by about 4 orders of magnitude, and thereby significantly improves the TE performance with the highest ZT value of 0.62 0.67 at $\sim 923 \mathrm{~K}$. This value is $9 \sim 10$ times that of pristine $\gamma-\mathrm{In}_{2} \mathrm{Se}_{3}$, proving that lithiation in $\gamma-\mathrm{In}_{2} \mathrm{Se}_{3}$ is playing a great role to improve the TE performance.

\section{Experimental}

Sample preparations Two elemental powders of In and Se with the purity of more than $99.999 \%$ were loaded into the vacuum silica tube, according to the stoichiometry $\mathrm{In}_{2} \mathrm{Se}_{3}$, and melted at $1273 \mathrm{~K}$ for $10 \mathrm{~h}$ followed by cooling to $950 \mathrm{~K}$ and holding at this temperature for $168 \mathrm{~h}$, then cooled to RT rapidly. The as - solidified ingots were pulverized in agate mortar and then ball milled in stainless-steel bowls containing benzinum at a rotation rate of $350 \mathrm{rpm}$ for $10 \mathrm{~h}$. A pure $\mathrm{\gamma}-\mathrm{In}_{2} \mathrm{Se}_{3}$ powder was obtained using above technologies.

Prior to lithiation via chemical diffusion, the powder of $\gamma-\mathrm{In}_{2} \mathrm{Se}_{3}$ was sorted by using 200 mesh, thus allowing the powder with the size of $\sim 20 \mu \mathrm{m}$ to be obtained. Subsequently, the sorted powder was soaked in the lithium acetate $\left(\mathrm{CH}_{3} \mathrm{COOLi}\right)$ solution for Li diffusion. Owing to the large chemical diffusivity (D) of $\mathrm{Li}\left(\mathrm{D}=10^{-13} \mathrm{~cm}^{2} \mathrm{~s}^{-1}\right.$ to $5.5 \times 10^{-10} \mathrm{~cm}^{2} \mathrm{~s}^{-1}$ ) in the $\mathrm{In}_{2} \mathrm{Se}_{3}$ solution, ${ }^{22}$ the $\mathrm{Li}$ concentration could be easily get saturated. We therefore determine that the longest lithiation time is $40 \mathrm{~h}$ at a fixed temperature of $50 \mathrm{C}^{\circ}$. Another diffusion practice was to vary lithiation temperature from $30 \mathrm{C}^{\circ}$ to $60 \mathrm{C}^{\circ}$ for a fixed lithiation time of $30 \mathrm{~h}$. After different lithiation processes, the lithiated powders were cleaned using alcohol for several times prior to drying.

The dried powders were directly sintered using a spark plasma sintering apparatus (SPS-1030) under a pressure of $55 \mathrm{MPa}$ and at the highest temperature of $950 \mathrm{~K}$. The total sintering time was less than $2 \mathrm{~min}$, including holding time (30 s) at this temperature. After sintering, the sample was cooled to RT rapidly. Such a rapid sintering procedure could avoid the phase transition caused by the interdiffusion of elements. ${ }^{13,23,24}$ After sintering, the consolidated samples were annealed at $950 \mathrm{~K}$ for 72 $h$ once more to ensure the pure $\gamma-\mathrm{In}_{2} \mathrm{Se}_{3}$ to be obtained. The density ( $d$ ) of the sintered samples, measured using Archimedes' method, is $~ 5.34 \times 10^{3}$ $\mathrm{kgm}^{-3}$, which is about $95 \%$ theoretical one. ${ }^{18}$ Two types of samples were prepared: parallel $\left(C_{/ /}\right)$and perpendicular $\left(C_{\perp}\right)$ to the pressing directions. They were all cut into $3 \mathrm{~mm}$ slices in width from the cylindrical- $\left(\phi \sim 13.0 \times 14.0 \mathrm{~mm}^{2}\right)$ and coin-shaped $(\phi$ $20 \times 3.0 \mathrm{~mm}^{2}$ ) bulks, and then polished to be $2.5 \times 12$ $\mathrm{mm}^{2}$ for electrical property measurements. The samples with $\phi 10.0 \times 2.0 \mathrm{~mm}^{2}$ in $C_{/ /}$and $C_{\perp}$ were prepared for thermal diffusivity and heat capacity measurements.

Structural analyses and calculation The powder $X$-ray diffraction (XRD) patterns were obtained on a Bruker D8 Advance instrument with $\mathrm{Cu} \mathrm{K} \alpha$ radiation $(\lambda=0.15406 \mathrm{~nm})$ with a scanning step size of $0.02^{\circ}$.

In order to gain a deep understanding of the crystal structure, the microstructure of lithiated $\mathrm{\gamma}$ - $\mathrm{In}_{2} \mathrm{Se}_{3}$ sample (lithiation time $30 \mathrm{~h}$ at $50 \mathrm{C}^{\circ}$ ) was examined by using high resolution transmission ${ }^{2}$ 
electron microscopy (HRTEM) (JEM-2010F, 220 kV). Besides, electron energy loss spectroscopy (EELS) data were acquired using a Gatan Model 776 Enfina spectrometer coupled to the JEM-2010F.

The band structures and formation energies upon $\mathrm{Li}$ occupation at different lattice sites were calculated using first principle calculation. During calculations, the DFT calculation were carried out within the framework of the plane-wave projector augmented wave formalism as implemented in the Vienna ab-initio Simulation Package (VASP). ${ }^{25}$ The generalized gradient approximation (GGA) to the exchange-correlation potential in the Perdew Burke Ernzerhof (PBE) form was used. ${ }^{26}$ A plane - wave cutoff energy of $500 \mathrm{eV}$ was used. Brillouin zone sampling scheme of Monkhorts-Pack k-mesh with $6 \times 6 \times 2$ was used to generate the $k$ points for calculations. The ground - state structure was obtained to a maximal force on each ion of less than $0.01 \mathrm{eV} / \AA$ and the total energy change of less than $1 \times 10^{-6} \mathrm{eV}$. A supercell consisting of $2 \times 2 \times 1$ unit cells of $\gamma-\mathrm{In}_{2} \mathrm{Se}_{3}$ were used for defect calculations. The $1 s^{2} 2 s^{1}, 5 s^{2} 5 p^{1}$, and $4 s^{2} 4 p^{4}$ were treated as valence states of $\mathrm{Li}$, In and $\mathrm{Se}$, respectively.

Measurements of physical properties Hall carrier concentrations $\left(n_{\mathrm{H}}\right)$ were determined using Hall coefficient $\left(R_{\mathrm{H}}\right)$ at RT measured using a PPMS system. Four-contact Hall-bar geometry $\left(2 \times 2 \times 7 \mathrm{~mm}^{3}\right)$ was used for the measurement. The $n_{\mathrm{H}}$ and $\mu$ values were estimated according to the formula $n_{\mathrm{H}}=1 / e R_{\mathrm{H}}$ and $\mu=\left|R_{H}\right| \sigma$ respectively, where $e$ is the electronic charge.

Electrical conductivities $(\sigma)$ and Seebeck coefficients $(\alpha)$ were measured simultaneously under $\mathrm{He}$ atmosphere from RT to $930 \mathrm{~K}$ on a ULVAC-RIKO ZEM-3 instrument system with the uncertainty each $<6 \%$. The thermal diffusivity $(\lambda)$ and heat capacity $\left(C_{\mathrm{p}}\right)$ were measured by the TC $-1200 \mathrm{RH}$ at RT 930 K with the uncertainty less than $10 \%$ respectively. The thermal conductivities $(\kappa)$ were calculated from $\kappa=$ $d C_{\mathrm{p}} \lambda$, here $d$ is the material density. The lattice contributions $\left(\kappa_{\mathrm{L}}\right)$ were attained from the total $\kappa$ minus the electronic part $\kappa_{\mathrm{e}} . \kappa_{\mathrm{e}}$ is estimated by the Wiedemann-Franz (W-F) relation, $\kappa_{\mathrm{e}}=L_{0} \sigma T$, where $L_{0}$ is the Lorenz constant estimated according to the

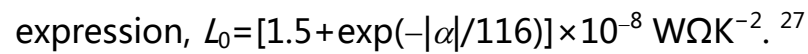

The above data obtained were repeated several times using different samples, and the average data for each parameter was attained. The total uncertainty for ZT was $\sim 22 \%$. In addition, in order to check the thermal stability of the $\gamma-\mathrm{In}_{2} \mathrm{Se}_{3}$ after lithiation, we have specially measured the TE properties from high temperature $(930 \mathrm{~K})$ to RT (cooling cycle) of the sample $\left(C_{/ /}\right)$with the lithiation time of $30 \mathrm{~h}$ at $50 \mathrm{C}^{\circ}$.

\section{Results and discussions}

Structural analyses Fig.S1 shows the $\mathrm{X}$ - ray diffraction patterns for the lithiated powders with different soaking times (Fig.S1a) and temperatures (Fig.S1b). All diffraction peaks in the patterns are identical to those of $\gamma-\mathrm{In}_{2} \mathrm{Se}_{3}$ phase (PDF: $40-1407$ : hexagonal crystal structure and space group $P \sigma_{1}$ ) with no visible impurity phases identified, indicating that the main phase is $\gamma-\mathrm{In}_{2} \mathrm{Se}_{3}$.

To characterize the microstructures and chemical compositions of lithiated $\gamma-\mathrm{In}_{2} \mathrm{Se}_{3}$ powders, we have carried out EDS, high-resolution TEM (HRTEM), and electron diffraction (ED) studies. Fig.S2a shows the low-magnification TEM image of a lithiated $\gamma-\mathrm{In}_{2} \mathrm{Se}_{3}$ powder for $30 \mathrm{~h}$ lithiation at a fixed temperature of $50 \mathrm{C}^{\circ}$, in which a typical polycrystalline structure is presented. Fig.S2b is its HRTEM image, inset in Fig.S2b is an enlarged image, where the crystal planes (113) and (110), corresponding to the periodic spacing of $0.31 \mathrm{~nm}$ and $0.36 \mathrm{~nm}$ in $\gamma-\mathrm{In}_{2} \mathrm{Se}_{3}$, are represented respectively. Fig.1 is an electron diffraction (SAED) pattern from a selected area, which matches well with the lattice structure in Fig.S2b, confirming the structure of $\mathrm{\gamma}-\mathrm{In}_{2} \mathrm{Se}_{3}$. Inset in Fig. 1 is the EDS spectrum, where only In and Se elements are identified without Li signal. It is likely that $\mathrm{Li}$ element is too small (light) to be detected. The $\mathrm{Cu}$ peaks in the spectrum come from $\mathrm{Cu}$ grid. 
Besides, EDS reveals that the lithiated $\gamma-\operatorname{In}_{2} \mathrm{Se}_{3}$ powder has a Se/In atomic ratio of $\sim 1.51$, proving the structure and composition of $\gamma-\mathrm{In}_{2} \mathrm{Se}_{3}$.

Although Li can penetrate into most materials, its atomic size is too small to be identified using EDS spectrum. Therefore, Electron Energy Loss Spectroscopy (EELS) is used to characterize the change in chemical composition in the current lithiated $\gamma-\mathrm{In}_{2} \mathrm{Se}_{3}$ powders. The EELS from the pristine $\mathrm{Y}-\mathrm{In}_{2} \mathrm{Se}_{3}$ and that for $30 \mathrm{~h}$ lithiation at $50 \mathrm{C}^{\circ}$ are shown in Fig.2. Before lithiation, the EEL spectrum reveals only a small peak centered around $56 \mathrm{eV}$, which should be assigned to the Se core level (Fig.2a), and inset in Fig.2a is its TEM image. Fig.2b is its corresponding line spectrum with background subtracted. However, after $30 \mathrm{~h}$ lithiation at $50 \mathrm{C}^{\circ}$, a large peak around $56 \mathrm{eV}$ can be clearly observed, as shown in Fig.2c, which is assigned to the core levels of Li K-edge structure mixed with Se, indicating the presence of $\mathrm{Li}$ in this material. An inset in Fig.2c is its TEM image. Fig.2d is its corresponding line spectrum with background subtracted. However, the onset of the Li peak position $(54 \mathrm{eV})$ is a little lower than that reported (58 eV) in ref. [17], which might be due to different crystal structure or space group of studied $\mathrm{In}_{2} \mathrm{Se}_{3}$.

Upon $\mathrm{Li}$ occupation in the lattice of $\gamma-\mathrm{In}_{2} \mathrm{Se}_{3}$, some changes of the lattice constants of the crystal have been taken place. The lattice constants $a$ and $c$ as a function of lithiation time (at $50 \mathrm{C}^{\circ}$ ) or lithiation temperature (for $30 \mathrm{~h}$ ), determined from the refinement of the $X$-ray patterns using Jade software, are shown in Fig.3a and Fig.3b respectively. The $a$ (7.056 7.090 $\AA$ ) and $c(19.30 \sim 19.35 \AA$ ) values for the pristine $\gamma-\mathrm{In}_{2} \mathrm{Se}_{3}$, which are in almost agreement with the results reported, ${ }^{12,18,19,28}$ increase with lithiation time until $30 \mathrm{~h}$ is reached (Fig.3a). Similarly, the average $a$ and $c$ values increase with lithiation temperature until $50 \mathrm{C}^{\circ}$ is reached (Fig.3b). Combining with the above results, we believe that $\mathrm{Li}$ concentration gets saturated for the lithiation time $30 \mathrm{~h}$ at $50 \mathrm{C}^{\circ}$. Higher lithiation temperature than 50
$\mathrm{C}^{\circ}$ or longer lithiation time than $30 \mathrm{~h}$ gives rise to possible release of $\mathrm{Li}$ ion from the material, thus shrinking the lattice structure.

The variations in lattice constants $a$ and $c$ can be directly confirmed by taking a close look at the peak position shifts in the XRD patterns (see enlarged patterns in Fig.S1), where the main peak positions $(110,006,300)$ move toward lower $2 \theta$ values with the lithiation time or temperature increasing until 30 $\mathrm{h}$ or $50 \mathrm{C}^{\circ}$ is reached. While the peak position moves toward higher angle as the lithiation time or temperature is increased to $40 \mathrm{~h}$ or $60 \mathrm{C}^{\circ}$.

Transport properties In order to probe the effect of $\mathrm{Li}$ diffusion into the crystal lattice, we have measured the Hall coefficients $\left(R_{\mathrm{H}}\right)$ at RT and then calculated the Hall carrier concentration $\left(n_{\mathrm{H}}\right)$ and mobility $(\mu)$. The results are shown in Fig.4. The $n_{H}$ and $\mu$ values as a function of lithiation time are shown in Fig.4a, where we observed that the mean $n_{\mathrm{H}}$ value increases rapidly from $3.64 \times 10^{14} \mathrm{~cm}^{-3}$ (pristine $\mathrm{\gamma}-\mathrm{In}_{2} \mathrm{Se}_{3}$ ) to $1.71 \times 10^{18} \mathrm{~cm}^{-3}$ (30 $\mathrm{h}$ lithiation), $\sim 4$ orders of magnitude of initial value, and then deceases to $6.30 \times 10^{16} \mathrm{~cm}^{-3}(40 \mathrm{~h})$. While the $\mu$ value decreases gradually from $26.57 \mathrm{~cm}^{2} \mathrm{v}^{-1} \mathrm{~s}^{-1}$ to the minimum value $2.04 \mathrm{~cm}^{2} \mathrm{v}^{-1} \mathrm{~s}^{-1}(30 \mathrm{~h})$, and then increases to $5.28 \mathrm{~cm}^{2} \mathrm{v}^{-1} \mathrm{~s}^{-1}$ (40 h). A similar lithiation temperature dependences of $n_{\mathrm{H}}$ and $\mu$ are observed, see Fig.4b. The $n_{\mathrm{H}}$ value increases with lithiation temperature increasing until $50 \mathrm{C}^{\circ}$ is reached, while the $\mu$ value decreases to the minimum at $50 \mathrm{C}^{\circ}$. Therefore, it is concluded that the lithiated $\gamma-\mathrm{In}_{2} \mathrm{Se}_{3}$ sample for a lithiation time of $30 \mathrm{~h}$ at $50 \mathrm{C}^{\circ}$ gives the highest Hall carrier concentration and lowest mobility. The results coincide well with the variation of the lattice constants, i.e., the higher the Hall carrier concentration after lithiation, the larger the unit cell.

TE performance Since lithiation in $\gamma-\mathrm{In}_{2} \mathrm{Se}_{3}$ gives rise to a significant enhancement in Hall carrier concentration, a remarkable improvement in electrical conductivity ${ }^{29,30}$ and TE performance are anticipated. 
Fig.5a is the Seebeck coefficients $(\alpha)$ perpendicular to the pressing direction $\left(C_{\perp}\right)$ as a function of lithiation temperature for the fixed lithiation time of $30 \mathrm{~h}$. The $\alpha$ values are negative, indicating $\mathrm{n}$ - type semiconducting behavior. Generally, the absolute $\alpha$ value $(|\alpha|)$ decreases with lithiation temperature increasing below the measuring temperature $830 \mathrm{~K}$ until the lithiation temperature $50 \mathrm{C}^{\circ}$ is reached. Above $830 \mathrm{~K}$ the $|\alpha|$ value gradually converges, and at $923 \mathrm{~K}$ it reaches 180.0 210.0 $\mathrm{MVK}^{-1}$ for the lithiated samples. The electrical conductivity $(\sigma)$, shown in Fig.5b, increases with lithiation temperature increasing until the lithiation temperature $50 \mathrm{C}^{\circ}$ is reached. The highest $\sigma$ value is $1.08 \times 10^{4} \Omega^{-1} \mathrm{~m}^{-1}$ (lithiation $30 \mathrm{~h}$ at $50 \mathrm{C}^{\circ}$ ) at the measuring temperature $923 \mathrm{~K}$. This value is about 39 times that of pristine $\gamma-\mathrm{In}_{2} \mathrm{Se}_{3}$, which suggests that the lithiation in $\gamma-\mathrm{In}_{2} \mathrm{Se}_{3}$ is an effective way to improve the electrical conductivity. Combined with the carrier concentrations shown in Fig.4, the $n_{\mathrm{H}}$ and $\sigma$ values reach the highest simultaneously among the samples when the lithiation temperature and time are at $50 \mathrm{C}^{\circ}$ and 30 h.

Fig.5c presents the lattice thermal conductivity $\left(\kappa_{\mathrm{L}}\right)$ against lithiation temperature for a fixed lithiation time of $30 \mathrm{~h}$. Most samples have relatively constant $\kappa_{\mathrm{L}}$ values at high measuring temperatures, except for the sample with lithiation at $60 \mathrm{C}^{\circ}$, which decreases with measuring temperature increasing. The reason is unclear. With the lithiation temperature increasing to $50 \mathrm{C}^{\circ}$, the sample gives the lowest $\kappa_{\mathrm{L}}$ values below $370 \mathrm{~K}$ and at $923 \mathrm{~K}$ its $\kappa_{\mathrm{L}}$ value is $0.34 \mathrm{WK}^{-1} \mathrm{~m}^{-1}$. Inset in Fig. $5 c$ is the total thermal conductivities $(\kappa)$, which bear a resemblance to the $\kappa_{\mathrm{L}}$. An exception is that the $\kappa$ values for most samples increase with temperature increasing at high temperatures. We believe that the increased $\kappa$ values at high temperatures should not come from the contribution of bipolar effect, ${ }^{31}$ because it is usually difficult to observe the bipolar effect in the wide gap semiconductors, like $\gamma-\mathrm{In}_{2} \mathrm{Se}_{3}$ with $E_{\mathrm{g}}>1.0 \mathrm{eV}$ from calculation and $1.9 \mathrm{eV}$ reported. ${ }^{16}$ In this regard, we speculate that there is an another contribution in the $\gamma-\mathrm{In}_{2} \mathrm{Se}_{3}$ - based solid solutions. Since the linear lattice thermal conductivity $-\mathrm{I} / T$ relation is expected to hold only for temperatures above the Debye characteristic temperature, $\theta_{D}$ therefore, the constant $\kappa_{\mathrm{L}}$ values for most samples at high temperatures might involve the contribution of photon conduction, $\kappa_{p}$, described below, ${ }^{32}$ although the photon conduction may usually be seen in some polycrystalline oxides, such as $\mathrm{BaO}$ and $\mathrm{SrO}_{1}{ }^{33} \mathrm{Al}_{2} \mathrm{O}_{3}$ and $\mathrm{BeO}_{1}{ }^{34}$ and in single crystals of $\mathrm{Al}_{2} \mathrm{O}_{3}, \mathrm{MgO}, \mathrm{CaF}_{2}$ and $\mathrm{TiO}_{2}{ }^{35}$

$$
\kappa_{\mathrm{p}}=16 / 3 \sigma r^{2} T^{3} / \mathrm{R}
$$

here $r$ is the refractive index in the medium, $k_{R}$ the mean free path of photons. The $\kappa_{p}$ value is proportional to $T^{3}$. Alternatively, the $\kappa$ values might involve the contribution of peripheral phonons, ${ }^{36-37}$ which increases with the measuring temperature increasing, especially, when the donor levels merge with the conduction band ${ }^{36-37}$ (see the electronic structure calculation results below). The third possibility might be the diminution of the structural deformation upon interstitial occupation of Li, which gives rise to less perturbation to the transport of most high - frequency phonons. ${ }^{38}$ Anyhow, the abnormal increasing of the total thermal conductivity $(\kappa)$ at high temperatures requires further investigations.

Combined with the three physical parameters $(\alpha$, $\sigma, \kappa)$, the dimensionless TE figure of merit $(Z T)\left(C_{\perp}\right)$ can be obtained. As expected, the $Z T$ value increases with lithiation temperature increasing until the lithiation temperature $50 \mathrm{C}^{\circ}$ is reached (Fig.5d). The highest ZT value is 0.67 at $\sim 923 \mathrm{~K}$. This $\mathrm{ZT}$ value is about 10 times that of pristine $\gamma-\operatorname{In}_{2} \mathrm{Se}_{3}$. Although the $\mathrm{ZT}$ value is still much lower than those of the state-of-the-art binary selenides reported (such as SnSe: $\mathrm{ZT}=2.6$ at $923 \mathrm{~K}_{i}^{4} \mathrm{In}_{4} \mathrm{Se}_{3}: \mathrm{ZT}=1.48$ at $705 \mathrm{~K}{ }^{39}$ ), it is worth noting that the $\mathrm{ZT}$ value of pristine $\mathrm{Y}-\mathrm{In}_{2} \mathrm{Se}_{3}$ is only $\sim 0.064$ at $\sim 923 \mathrm{~K}$, indicating that a5 
big improvement has been achieved after lithiation. This finding also implies that lithiation in the materials with intrinsic vacancies is an effective approach on the improvement of TE performance, even if the pristine materials behave like insulators.

The TE performance of lithiated $\gamma-\mathrm{In}_{2} \mathrm{Se}_{3}(\mathrm{C} \perp)$ for different lithiation times ( $\leq 40 \mathrm{~h}$ ) at a fixed lithiation temperature of $50 \mathrm{C}^{\circ}$ is shown in the Fig.6. With the lithiation time increasing, the absolute Seebeck coefficient gradually decreases (Fig.6a), while the electrical conductivity increases (Fig.6b). Similarly, the sample with the lithiation time of $30 \mathrm{~h}$ gives relatively low lattice contribution ( $\kappa_{\mathrm{L}}$ ) (Fig.6c) and total thermal conductivities ( $\kappa$ ) (inset in Fig.6c) at high temperatures. Accordingly, the sample with 30 $\mathrm{h}$ of lithiation at $50 \mathrm{C}^{\circ}$ possesses the highest ZT value in this set of samples (Fig.6d). Besides, the sample with lithiation time of $40 \mathrm{~h}$ has an increased $\kappa$ values at high temperatures.

The TE performance parallel to the pressing direction $\left(C_{/ /}\right)$at a fixed lithiation temperature $\left(50 \mathrm{C}^{\circ}\right)$ or time $(30 \mathrm{~h})$ are presented in Fig.S3. The results bear resemblance to those of the samples $\left(C_{\perp}\right)$. Likewise, the lithiated sample $\left(C_{/ /,}, 30 \mathrm{~h}\right.$ at $\left.50 \mathrm{C}^{\circ}\right)$ gives the highest electrical $\left(1.11 \times 10^{4} \Omega^{-1} \mathrm{~m}^{-1}\right)$, lowest lattice thermal conductivity $\left(0.30 \mathrm{WK}^{-1} \mathrm{~m}^{-1}\right)$, and highest ZT value (0.62) at $\sim 923 \mathrm{~K}$, about 9 times that of the pristine $\gamma-\mathrm{In}_{2} \mathrm{Se}_{3}$.

As stated above, $\mathrm{In}_{2} \mathrm{Se}_{3}$ has multiple phases in the temperature range from $\mathrm{RT}$ to $1150 \mathrm{~K}_{1}^{19,40}$ each of which is stable in its own existing temperature range. However, the mutual transformation between them easily occurs as the temperature elevates or drops, therefore, it is necessary to check the stability of $\gamma-\mathrm{In}_{2} \mathrm{Se}_{3}$, especially, the stability of $\mathrm{Li}$ ion in the $\gamma-\mathrm{In}_{2} \mathrm{Se}_{3}$ matrix. In this work a cooling cycle measurement of the TE properties has been specially conducted for the sample $\left(\mathrm{C}_{/ /}\right)$(lithiation for $30 \mathrm{~h}$ at $50 \mathrm{C}^{\circ}$ ). The results are shown in Fig.7, where we observed that there is no big change of the electrical conductivities and absolute Seebeck coefficients between the heating and cooling cycles (Fig.7a and b), but the thermal conductivities $(\kappa)$ are a little higher than those from the heating cycle (Fig.7c), an inset in Fig.7c is the lattice contribution $\kappa_{\mathrm{L}}$. The resultant ZT values in the cooling cycle are about $\sim 20 \%$ lower than those in the heating one above $810 \mathrm{~K}$ (Fig.7d). The degradation in TE performance could not be attributed to the release of the Li ions or the reduction of the carrier concentration, because only a limited change of the electrical properties $(\sigma, \alpha)$ has been taken place, nor could it be due to the change of the chemical compositions, since the ratio of Se/In keeps $\sim 1.5$ after cooling cycle, determined by EDAX analysis (see Fig.S4). The possible reason might be due to the decreased phonon scattering (see inset in Fig.7c) caused by the increased crystallinity after cooling cycle (see the XRD analysis in Fig.S5) if compared with that of assolidified ingot. Besides, no visible impurity phases and phase changes were identified after cooling cycle, according to Fig.S5.

Lithiation via chemical or electrochemical route has been extensively applied in $\alpha-\operatorname{In}_{2} \mathrm{Se}_{3}$ to improve the electrical conductivity of microbatteries, ${ }^{20,41,42}$ because the $\alpha-\mathrm{In}_{2} \mathrm{Se}_{3}$ has a layer - like crystal structure. The bonding inside the layers of $\alpha-\operatorname{In}_{2} \mathrm{Se}_{3}$ is strongly covalent, while the interlayer interaction (Se-Se) is of the Van der Waals type. Therefore, Li is easily intercalated into the Van der Waals gap. Although $\gamma-\mathrm{In}_{2} \mathrm{Se}_{3}$ does not have a layer - like structure, it is of ordered vacancies in screw form (VOSF). ${ }^{17,19,43,44}$ These vacancies are still capable of accommodating foreign impurities, such as $\mathrm{Li}^{+}$ through diffusion, which expands the unit cell. That is the reason why we have observed the increasing of the lattice constants $a$ and $c$ (Fig.3).

On the other hand, the ion transport in mixed electronic and ionic conductors proceeds through the simultaneous movement of electrons. If the requirement of local electrical neutrality is taken into consideration, one condition should be set for a monovalent ion as $\mathrm{Li}^{+}$, that is: the diffusion flux of 6 
$\mathrm{Li}^{+}\left(U_{\mathrm{Li}+}\right)$ should be equal to that of electrons $\left(J_{\mathrm{e}}-\right)$ upon equilibrium,

$$
\rho_{\text {Li+ }}=J_{\mathrm{e}^{-}}
$$

This suggests that the charge transferring between guest species and host structure are lithiation temperature and time dependent. This explains why the highest carrier concentration has observed under the specific lithiation condition (Fig.4).

In order to further elucidate the origin of the carrier concentration enhancement caused by the $\mathrm{Li}^{+}$ insertion into the $\gamma-\mathrm{In}_{2} \mathrm{Se}_{3}$, we have specially calculated the band structures using the first principle calculation. Fig.8a is showing the band structure and corresponding density of states (DOS) of $\gamma$ - $\mathrm{In}_{2} \mathrm{Se}_{3}$, where the Fermi level $\left(F_{\mathrm{r}}\right)$ is located on the edge of valence band maximum (VBM). The electron transport properties are determined by the states near the conduction band minimum (CBM), which are coming from the strong coupling of the In $-\mathrm{s}$ and $\mathrm{Se}-\mathrm{p}$ states, while the hole transport properties are mainly governed by the states near the VBM which are mainly from Se-p state. Fig.8b shows the $3 \mathrm{D}$ electron localization function (ELF) isosurfaces maps of $\gamma-\mathrm{In}_{2} \mathrm{Se}_{3}$ for $\mathrm{ELF}=0.8$ and $\mathrm{ELF}=0.9$, which show a lobe-shaped asymmetrically localized electron cloud around $\mathrm{Se}^{2-}$, indicating the degree of electron localization. Since there are lone-pair electrons surrounding Se atoms from the maps along with the activity of the $\mathrm{Se}-\mathrm{p}$ state near the $\mathrm{VBM}$, we therefore presume that the pristine $\gamma-\mathrm{In}_{2} \mathrm{Se}_{3}$ should have a low electrical conductivity. This calculation is in agreement with the experimental results, as shown in Fig.5b and $6 \mathrm{~b}$.

Fig.9 presents the formation energies $\left(E_{\mathrm{f}}\right)$ of defects as a function of the Fermi energy $\left(F_{\mathrm{r}}\right)$ under the $\mathrm{Se}$-rich and $\mathrm{Se}$-poor conditions, based on the relationships below:

$$
\begin{aligned}
& E_{\mathrm{f}}=E_{\mathrm{tot}}[\text { defect }]-E_{\mathrm{tot}}[\mathrm{ref}]-\mu[\mathrm{Li}]+\mu[\mathrm{In} \text { or Se }]+q \\
& \left(E_{\mathrm{f}}+E_{\mathrm{v}}+\Delta V\right. \\
& \mu[\mathrm{Se}]_{\min }=\left(E\left[\mathrm{In}_{2} \mathrm{Se}_{3}\right]-2 \mu[\mathrm{In}]_{\mathrm{bulk}}\right) / 3
\end{aligned}
$$

here $E_{\mathrm{tot}}[$ ref $]$ denotes the total energy of the perfect-crystal supercell, $\mu[$ Li] chemical potential of $\mathrm{Li}^{+}, q$ : charge state, $E_{\mathrm{v}}$ valence band maximum in the bulk, $\Delta V$ alignment of the average electrostatic potential in the defect supercell with that in the bulk. $\mu[\mathrm{Se}]_{\min }$ represents lower limit potential of Se corresponding to the Se - poor (In - rich) limit potential. When calculating the $E_{\mathrm{f}}$ upon $\mathrm{Se}$ - rich (In - poor) conditions, upper limit potential of Se $\mu[\mathrm{Se}]_{\max }=\mu[\mathrm{Se}]_{\text {bulk }}$ is used. $\mu[\mathrm{In}]_{\text {bulk }}$ is the chemical potential of In in In crystal, and $E\left[\mathrm{In}_{2} \mathrm{Se}_{3}\right]$ formation energy for the perfect $\mathrm{In}_{2} \mathrm{Se}_{3}$. Based on the results in Fig.9, it is obvious that $\mathrm{Li}^{+}$prefers the interstitial site $\left(\mathrm{Li}_{i}{ }^{1+}\right)$ for Se-rich condition. Besides, it is possible for $\mathrm{Li}$ to occupy $\mathrm{Se}\left(\mathrm{Li}_{\mathrm{Se}}{ }^{2+}\right)$ or interstitial sites at low Fermi energy at Se-poor condition. However, Li ions preferentially occupy the interstitial sites as Fermi energy increases, and have the least possibility to occupy the In sites $\left(\mathrm{Li}_{\mathrm{In}}{ }^{0}\right)$.

Owing to the $\mathrm{Li}$ incorporation interstitially in - $\mathrm{In}_{2} \mathrm{Se}_{3}$, the lattice constants $a$ and $c$ show an increasing tendency, as indicates in Table 1 , although $a(7.337 \AA)$ and $c(19.71 \AA)$ values from calculation are larger than those of experimental

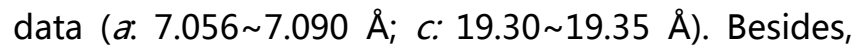
the $a$ and $c$ values for the case of Li substitution for Se is the smallest due to much smaller atomic radius of $\mathrm{Li}$ than that of Se. Therefore, the dominating occupation of Li should be in the interstitial sites, based on the variation of lattice constants $a$ and $c$ values.

Since the electronic level of $\mathrm{Li}^{+} / \mathrm{Li}$ is far above the Fermi level $\left(F_{\mathrm{r}}\right)_{1}{ }^{22}$ the occupied $\mathrm{Li}$ should remain ionized $\mathrm{Li}^{+}$. Upon $\mathrm{Li}^{+}$incorporation in $\gamma-\mathrm{In}_{2} \mathrm{Se}_{3}, F_{\mathrm{r}}$ unpins and moves into the conduction band. The donor levels seems to merge with the conduction band, see Fig.10a and Fig.10b. Although the bandgap has a limited change, it is suggested that the incorporated Li ions, acting as a donor, must locate within the band structure of the host and are responsible for the enhancement in carrier concentration (Fig.4). Inset in Fig.10a is the unit cell ${ }^{7}$ 
with Li occupation interstitially (here only one $\mathrm{Li}$ atom in the $2 \times 2 \times 1$ unit cell is represented). After the movement of $F_{\mathrm{r}}$ into the $\mathrm{CB}$, the effective mass of the conduction bands ( $C B$ ) in both cases is very small if compared with that of $V B$, which further supports the remarkable improvement of the electrical conductivity (see Fig.5, and 6).

\section{Conclusions}

Lithiation ofvy - $\mathrm{In}_{2} \mathrm{Se}_{3}$ powder has been conducted in the lithium acetate $\left(\mathrm{CH}_{3} \mathrm{COOLi}\right)$ solution, and the band structure and TE properties of lithiated samples have been examined. Through the measurement of Hall coefficients, we have observed that the Hall carrier concentration $\left(n_{H}\right)$ at RT is $1.71 \times 10^{18} \mathrm{~cm}^{-3}$ after $30 \mathrm{~h}$ lithiation at $50 \mathrm{C}^{\circ}$, increased by about 4 orders of magnitude compared to that of pristine $\gamma-\operatorname{In}_{2} \mathrm{Se}_{3}$. The highest electrical conductivities are $1.08 \times 10^{4} \Omega^{-1} \mathrm{~m}^{-1}(\sigma \perp)$ and $1.11 \times 10^{4}$ $\Omega^{-1} \mathrm{~m}^{-1}\left(\sigma_{I}\right)$ at $\sim 923 \mathrm{~K}$, about 40 times that of pristine $\gamma-\mathrm{In}_{2} \mathrm{Se}_{3}$ respectively. The first principle calculation reveals that $\mathrm{Li}^{+}$is energetically favorable to the interstitial sites in $\gamma$ - $\operatorname{In}_{2} \mathrm{Se}_{3}$, and that the Fermi level $\left(F_{\mathrm{r}}\right)$ unpins and moves to the conduction band (CB). The modification in band structures directly elucidates the origin of the remarkable improvement of electrical conductivity. Along with the lowest lattice thermal conductivity $\left(\kappa_{\mathrm{L}}\right)$ of the sample, the highest ZT value of $0.62 \sim 0.67$ was attained. This value is about 9 10 times that of pristine $\mathrm{Y}-\mathrm{In}_{2} \mathrm{Se}_{3}$.

\section{Supporting Information}

The X-ray diffraction patterns of the lithiated $\gamma-\mathrm{In}_{2} \mathrm{Se}_{3}$; HRTEM images for the sample (lithiation: $30 \mathrm{~h}$ and 50 $\mathrm{C}^{\circ}$ ); TE performance parallel to the pressing direction $\left(C_{/ /}\right)$; EPMA mapping of two elements In and Se on polished $\gamma-\mathrm{In}_{2} \mathrm{Se}_{3}$ surface; XRD pattern of the sample after measurement from high temperature to RT. The Supporting Information is available free of charge on the ACS Publications website at DOI: 10.1021/acs.chemmater.5b01389.

\section{AUTHOR INFORMATION}

* To whom correspondence should be addressed.

E-mail: cuijiaolin@163.com

\section{Author Contributions}

The manuscript was written through contributions of all authors. / All authors have given approval to the final version of the manuscript.

\section{Notes}

The authors declare no competing financial interest.

\section{ACKNOWLEDGMENT}

This work was supported by the National Natural Science Foundation of China (51671109, 51171084, 11604233), and Zhejiang Provincial Natural Science Foundation (LY14E010003, LQ14E010001).

\section{ABBREVIATIONS}

$\mathrm{TE}$, thermoelectric; $\mathrm{RT}$, room temperature; $\mathrm{CB}$, Conducrion; VB: Valence band

\section{REFERENCES}

(1) Pei, Y.; Shi, X.; LaLonde, A.; Wang, H.; Chen, L.; Snyder,

G. J. Convergence of Electronic Bands for High

Performance Bulk Thermoelectrics. Nature 2011, 473, $66-69$.

(2) Heremans, J. P.; Jovovic,V.; Toberer, E. S.; Saramat, A.; Kurosaki, K.; Charoenphakdee, A.; Yamanaka, S.; Snyder, G.

J. Enhancement of Thermoelectric Efficiency in PbTe by Distortion of the Electronic Density of States. Science 2008, 321, 554-557.

(3) Zhao, L.; Tan, G.; Hao, S.; He, J.; Pei, Y.; Chi, H.; Wang, H.; Gong, S.; Xu, H.; Dravid, V. P.; Uher, C.; Snyder, G. J.; Wolverton, C.; Kanatzidis, M. G. Ultrahigh Power Factor 
and Thermoelectric Performance in Hole-Doped

Single-Crystal SnSe. Science 2016, 351, 141-144.

(4) Zhao, L.; Lo, S.; Zhang, Y.; Sun, H.; Tan, G.; Uher, C.;

Wolverton, C.; Dravid, V. P.; Kanatzidis, M. G. Ultralow

Thermal Conductivity and High Thermoelectric Figure of

Merit in SnSe Crystals. Nature 2014, 508, 373-378.

(5) Polymeris, G. S.; Vlachos, N.; Khan, A. U.;

Hatzikraniotis, E.; Lioutas, Ch. B.; Delimitis, A.; Pavlidou, E.;

Paraskevopoulos, K. M.; Kyratsi, Th. Nanostructure and

Doping Stimulated Phase Separation in High - ZT

$\mathrm{Mg}_{2} \mathrm{Si}_{0.55} \mathrm{Sn}_{0.4} \mathrm{Ge}_{0.05}$ Compounds. Acta Mater. 2015, 83,

$285-293$.

(6) Pan, Y.; Li, J. Thermoelectric Performance

Enhancement in $\mathrm{N}$ - type $\mathrm{Bi}_{2}(\mathrm{TeSe})_{3}$ Alloys Owing To

Nanoscale Inhomogeneity Combined With a Spark

Plasma-Textured Microstructure. NPG Asia Mater. 2016, 8,

e275.

(7) Watanabe, Y. C.; Kanako, S. C.; Kawazoe, H.; Yamane,

M. Imperfections in Amorphous Chalcogenides. IV. A Model of Electrical Conduction Processes in Amorphous and Crystalline $\mathrm{In}_{2} \mathrm{Se}_{3}$. Phys. Rev. B 1989, 40, 3133-3142.

(8) Cui, J.; Liu, X.; Zhang, X.; Li, Y.; Deng, Y. Bandgap

Reduction Responsible for the Improved Thermoelectric

Performance of Bulk Polycrystalline $\operatorname{In}_{2-x} \mathrm{Cu}_{x} \mathrm{Se}_{3}(x=0-0.2) . J$.
Appl. Phys. 2011, 110, 023708.

(9) Cui, J.; Zhang, X. J.; Deng, Y.; Fu, H.; Yan, Y. M.; Gao, Y.

L.; Li, Y. Y. Modified Structures and Improved Thermoelectric Property in Ag - Added Polycrystalline $\mathrm{In}_{2} \mathrm{Se}_{3}$. Scripta. Mater. 2011, 64, 510-512.

(10) Cui, J.; Wang, L.; Du, Z.; Ying, P.; Deng, Y. High

Thermoelectric Performance of a Defect in $\alpha-\mathrm{In}_{2} \mathrm{Se}_{3}$-Based Solid Solution upon Substitution of $\mathrm{Zn}$ for In. J. Mater.

Chem. C. 2015, 3, 9069-9075.

(11) Likforman, A.; Foureroy, P. H.; Guittard, M.; Flahant, J.;

Poirier, R.; Szydlo, N. Transitions de la Forme de Haute Température $\alpha$ de $\mathrm{In}_{2} \mathrm{Se}_{3}$, de part et d'autre de la Température Ambiante. J. Solid State Chem. 1980, 33, 91-

97.

(12) Popović, S.; Tonejc, A.; Gržeta-Plenković, B.; Trojko, R. Revised and New Crystal Data for Indium Selenides. J. Appl. Crystallogr. 1979, 12, 416-420.

(13) Popović, S.; Čelustka, B.; Bidjin, D. X-Ray Diffraction Measurement of Lattice Parameters of $\mathrm{In}_{2} \mathrm{Se}_{3}$. Phys. Stat. Sol. a 1971, 6, 301-304.

(14) Eddike, D.; Ramdani, A.; Brun, G.; Tedenac, J. C.; Liautard, B. Phase Diagram Equilibria $\mathrm{In}_{2} \mathrm{Se}_{3}-\mathrm{Sb}_{2} \mathrm{Se}_{3}$ Crystal Growth of the $\beta-P h a s e \mathrm{In}_{1.94} \mathrm{Sb}_{0.06} \mathrm{Se}_{3}$. Mater. Res. Bull. 1998, 33, 519-523. 
(15) Landuyt, J. Van.; Tendeloo, G. Van.; Amelinckx, S.

Phase Transitions in $\mathrm{In}_{2} \mathrm{Se}_{3}$ as Studied by Electron

Microscopy and Electron Diffraction. Phys. Stat. Sol. a

$1975,30,299-314$.

(16) Marsillac, S.; Combot-Marie, A. M.; Bernède, J. C.;

Conan, A. Experimental Evidence of the Low-Temperature

Formation of $\gamma$-In ${ }_{2} \mathrm{Se}_{3}$ Thin Films Obtained by a Solid-State

Reaction. Thin Solid Films 1996, 288, 14-20.

(17) Peng, H.; Zhang, X. F.; Twesten, R. D.; Cui, Y. Vacancy

Ordering and Lithium Insertion in $\mathrm{II}_{2} \mathrm{VI}_{3}$ Nanowires. Nano

Res. 2009, 2, 327-335.

(18) Pfitzner, A.; Lutz, H. D. Redetermination of the Crystal Structure of $\gamma-\mathrm{In}_{2} \mathrm{Se}_{3}$ by Twin Crystal X-ray Method. J. Solid State Chem. 1996, 124, 305-308.

(19) Ye, J.; Soeda, S.; Nakamura, Y.; Nittomo, O. Crystal

Structure and Phase Transformation in $\mathrm{In}_{2} \mathrm{Se}_{3}$ Compound

Semiconductor. Jpn. J. Appl. Phys. 1998, 37, 4264-4271.

(20) Julien, C.; Balkanski, M. Optical and Electrical Transport Studies in $\mathrm{Li}_{0.1} \mathrm{In}_{2} \mathrm{Se}_{3}$. Mater. Sci. Eng. B 1996, 38,

$1-8$.

(21) Zhao, J.; Yang, L. Structure Evolutions and Metallic Transitions in $\mathrm{In}_{2} \mathrm{Se}_{3}$ Under High Pressure. J. Phys. Chem. C 2014, 118, 5445-5452.

(22) Julien, C.; Hatzikraniotis, E.; Chevy, A.; Kambas, K.
Electrical Behavior of Lithium Intercalated Layered In - Se

Compounds. Mater. Res. Bull. 1985, 20, 287-292.

(23) Julien, C.; Edurief, M.; Balkanski, M.; Hatzikraniotis, E.;

K. Kambas, Electrical Transport Properties of $\mathrm{In}_{2} \mathrm{Se}_{3}$. Phys.

Stat. Sol. a 1985, 88, 687-695.

(24) Yadav, A. A.; Salunke,S. D. Photoelectrochemical Properties of $\mathrm{In}_{2} \mathrm{Se}_{3}$ Thin Films: Effect of Substrate Temperature. J. Alloys Compd. 2015, 640, 534-539.

(25) Blöchl, P. E. Projector Augmented-Wave Method. Phys. Rev. B. Condens. Matter Mater. Phys. 1994, 50, 17953-17979.

(26) Perdew, J. P.; Burke, K.; Ernzerhof, M. Generalized Gradient Approximation Made Simple. Phys. Rev. Lett. 1996, 77, 3865-3868.

(27) Kim, H.; Gibbs, Z. M.; Tang, Y.; Wang, H.; Snyder, G. J. Characterization of Lorenz Number With Seebeck Coefficient Measurement. APL Mater. 2015, 3, 041506.

(28) Lutz, H. D.; Fischer, M.; Baldus, H. P.; Blachnik, R. Zur Polymorphie Des $\mathrm{In}_{2} \mathrm{Se}_{3}$. J. Less Common. Met. 1988, 143, 83-92.

(29) Chaiken, A.; Nauka, K.; Gibson, G. A.; Lee, H.; Yang, C. C.; Wu, J.; Ager, J. W.; Yu, K. M.; Walukiewicz, W. Structural and Electronic Properties of Amorphous and Polycrystalline $\mathrm{In}_{2} \mathrm{Se}_{3}$ Films. J. Appl. Phys. 2003, 94, 
$2390-2397$.

(30) Yudasaka, M.; Matsuoka, T.; Nakanishi, K. Indium

Selenide Film Formation by the Double-Source Evaporation of Indium and Selenium. Thin Solid Films 1987,

146, 65-73.

(31) Pei, Y.; Lensch-Falk, J.; Toberer, E. S.; Medlin, D. L.;

Snyder, G. J. High Thermoelectric Performance in PbTe Due to Large Nanoscale $\mathrm{Ag}_{2} \mathrm{Te}$ Precipitates and La Doping. $A d v$.

Funct. Mater. 2011, 21, 241-249.

(32) Lee, D. W.; Kingery, W. D. Radiation Energy Transfer and Thermal Conductivity of Ceramic Oxides. J. Am. Ceram. Soc. $1960,43,594-607$.

(33) Pengelly, A. E. Heat Transfer Through OxideCathode Materials. Brit. J. Appl. Phys. 1995, 6, 18-20.

(34) M. McQuarrie. Thermal Conductivity: VII, Analysis of Variation of Conductivity With Temperature for $\mathrm{Al}_{2} \mathrm{O}_{3}, \mathrm{BeO}$, and MgO. J. Am. Ceram. Soc. 1995, 37 [2, Part II], 91-95.

(35) Charvat, F. R.; Kingery, W. D. Thermal Conductivity: XIII. Effect of Microstructure on Conductivity of Single - Phase Ceramics. J. Am. Ceram. Soc. 1957, 40, 306-315.

(36) Dubey, K. S.; Verma, G. S. Role of Peripheral Phonons in the Lattice Thermal Conductivity of Doped Semiconductors: Application to n-Ge. Phys. Rev. B 1971, 4,
2071-2074.

(37) Badir Khan, Z.K.; Dubey, K.S. Peripheral Phonons and Phonon Conductivity of a Metal at Low Temperatures. Solid State Commun. 1981, 38, 279-282.

(38) Xu, Y.; Li, Z.; Duan, W. Thermal and Thermoelectric Properties of Graphene. Small 2014, 10, 2182-2199.

(39) Rhyee, J. S.; Lee, K.H.; Lee, S.M.; Cho, E.; Kim, S.II.; Lee, E.; Kwon, Y.S.; Shim, J.H.; Kotliar, G. Peierls Distortion as a Route to High Thermoelectric Performance in $\operatorname{In}_{4} \mathrm{Se}_{3}-\delta$ Crystals. Nature 2009, 459, 965-968.

(40) Emziane, M.; Marsillac, S.; Bernède, J. C. Preparation of Highly Oriented $\alpha-\mathrm{In}_{2} \mathrm{Se}_{3}$ Thin Films by a Simple Technique. Mater. Chem. Phys. 2000, 62, 84-87.

(41) Julien, C.; Khelfa, J. A.; Benramdane, N.; Guesdon, J. P.; Dzwonkowski, P.; Samaras, I.; Balkanski, M. Lithium Insertion in Indium Selenide Films: Application to Microbatteries. Mater. Sci. Eng. B 1994, 23, 105-115.

(42) Balkanski, M.; Kambas, K.; Julien, C.; Hammerberg,J.; Schleich, D. Optical and Transport Measurements on Lithium $\alpha-\mathrm{In}_{2} \mathrm{Se}_{3}$ Layered Compounds. Solid state lonics 1981, 5, 387-390.

(43) Balkanski, M.; Julien,C. Insertion cathodes for solid state microbatteries, solid state microbatteries, Ed: J. R. Akridge and M. Balkanski, Plenum Press, New York, 
1990, 269-292.

(44) Han, G.; Chen, Z.; Drennan, J.; Zou, J. Indium Selenides: Structural Characteristics, Synthesis and Their Thermoelectric Performances. Small 2014, 10, 2747-2763.

\section{Captions for figures}

Fig.1 SAED pattern of a lithiated $\gamma-\mathrm{In}_{2} \mathrm{Se}_{3}$ powder (for lithiation $30 \mathrm{~h}$ at a fixed temperature of $\left.50 \mathrm{C}^{\circ}\right)$. Inset: EDS spectrum, only In and Se elements are represented without Li signal. Cu peaks come from Cu grid.

Fig.2 (a) EEL spectrum of pristine $\gamma-\mathrm{In}_{2} \mathrm{Se}_{3}$ powder, inset is its TEM image, where a small peak around $\sim 56 \mathrm{eV}$ assigned to the Se core level; (b) Corresponding line spectrum of pristine $\gamma-\mathrm{In}_{2} \mathrm{Se}_{3}$ with background subtracted; (c) EEL spectrum of lithiated $\gamma-\mathrm{In}_{2} \mathrm{Se}_{3}$ powder with $30 \mathrm{~h}$ lithiation at $50 \mathrm{C}^{\circ}$, inset is its TEM image; (d) Corresponding line spectrum of lithiated $\gamma-\operatorname{In}_{2} \mathrm{Se}_{3}$, where a large peak centered at $\sim 56 \mathrm{eV}$, assigned to the Se mixed with Li core levels, was clearly observed.

Fig.3 The lattice constants $a$ and $c$ as a function of lithiation time (at a fixed lithiation temperature of $50 \mathrm{C}^{\circ}$ ) (a), and lithiation temperature (for a fixed lithiation time of $30 \mathrm{~h}$ (b), upon Li diffusion into the $\mathrm{\gamma}-\mathrm{In}_{2} \mathrm{Se}_{3}$.
Fig.4 Measured Hall carrier concentration $\left(n_{H}\right)$ and mobility $(\mu)$ of the lithiated $\gamma-\operatorname{In}_{2} \mathrm{Se}_{3}$ at a fixed lithiation temperature of $50 \mathrm{C}^{\circ}(\mathrm{a})$, and for a fixed lithiation time of $30 \mathrm{~h}(\mathrm{~b})$.

Fig.5 The thermoelectric properties of lithiated $\gamma-\mathrm{In}_{2} \mathrm{Se}_{3}$

$(\mathrm{C} \perp$ ) as a function of lithiation temperature for the fixed lithiation time of $30 \mathrm{~h}$. (a) Seebeck coefficient ( $\alpha$ ), (b) Electrical conductivity $(\sigma)$, (c) Lattice thermal conductivity $\left(\kappa_{\mathrm{L}}\right)$, insert is the total thermal conductivity $(\kappa),(\mathrm{d}) \mathrm{ZT}$ value. Fig.6 The thermoelectric properties of lithiated $\gamma-\mathrm{In}_{2} \mathrm{Se}_{3}$ $(C \perp)$ as a function of lithiation time at a fixed lithiation temperature of $50 \mathrm{C}^{\circ}$. (a) Seebeck coefficient $(\alpha)$, (b) Electrical conductivity $(\sigma)$, (c) Lattice thermal conductivity $\left(\kappa_{\mathrm{L}}\right)$, insert is the total thermal conductivity $(\kappa),(d)$ ZT value.

Fig.7 Measured thermoelectric properties of the sample

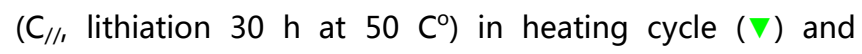
cooling cycle ( $\odot$ ). (a) Electrical conductivity $(\sigma)$, (b) Seebeck coefficient $(\alpha),(\mathrm{c})$ Total thermal conductivity $(\kappa)$, an inset is the lattice contribution $\left(\kappa_{\mathrm{L}}\right),(\mathrm{d}) \mathrm{ZT}$ value.

Fig. 8 (a) Band structure (left) and the density of states (DOS) (right) of $\gamma-\mathrm{In}_{2} \mathrm{Se}_{3}$. (b) 3D electron localization function (ELF) isosurfaces maps of $\gamma-\mathrm{In}_{2} \mathrm{Se}_{3}$ for $\mathrm{ELF}=0.8$ (left) and ELF=0.9 (right). ELF $=1$ corresponding to perfect localization and ELF $=1 / 2$ corresponding to the $e^{12}$ 
electron gas. The ELF of $\gamma-\mathrm{In}_{2} \mathrm{Se}_{3}$ shows a lobe-shaped asymmetrically localized electron cloud around $\mathrm{Se}^{2}-$, indicating the degree of electron localization.

Fig.9 Formation energies $\left(E_{f}\right)$ of defects as a function of the Fermi energy $\left(F_{\mathrm{r}}\right)$ under the $\mathrm{Se}$ - rich and $\mathrm{Se}-$ poor conditions.

Fig.10 (a) The band structure of Li interstitially occupied $\mathrm{\gamma}-\mathrm{In}_{2} \mathrm{Se}_{3}$, an inset is the relaxed structure of Li interstitially occupied $\gamma-\mathrm{In}_{2} \mathrm{Se}_{3}$ (here only one $\mathrm{Li}$ atom in the $2 \times 2 \times 1$ unit cell is represented, the dotted circled is the interstitial Li atom); (b) The band structure of Li occupying the Se sites. In both cases, the Fermi level $\left(F_{\mathrm{r}}\right)$ unpins and moves into the conduction band (CB).

\section{Table captions}

Table 1 The relaxed lattice constant of perfect bulk $\gamma^{-} \mathrm{In}_{2} \mathrm{Se}_{3}$, Li interstitial, Li substitution for Se and In.

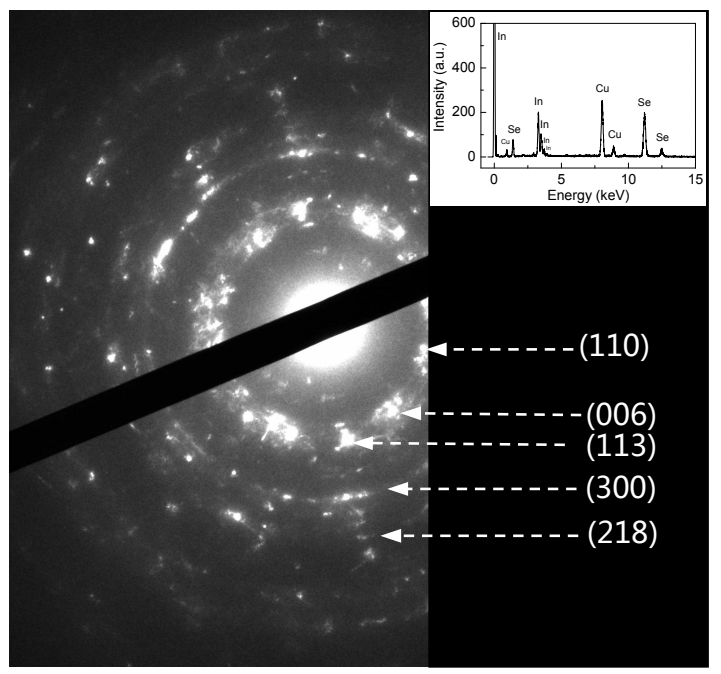

Figure 1 

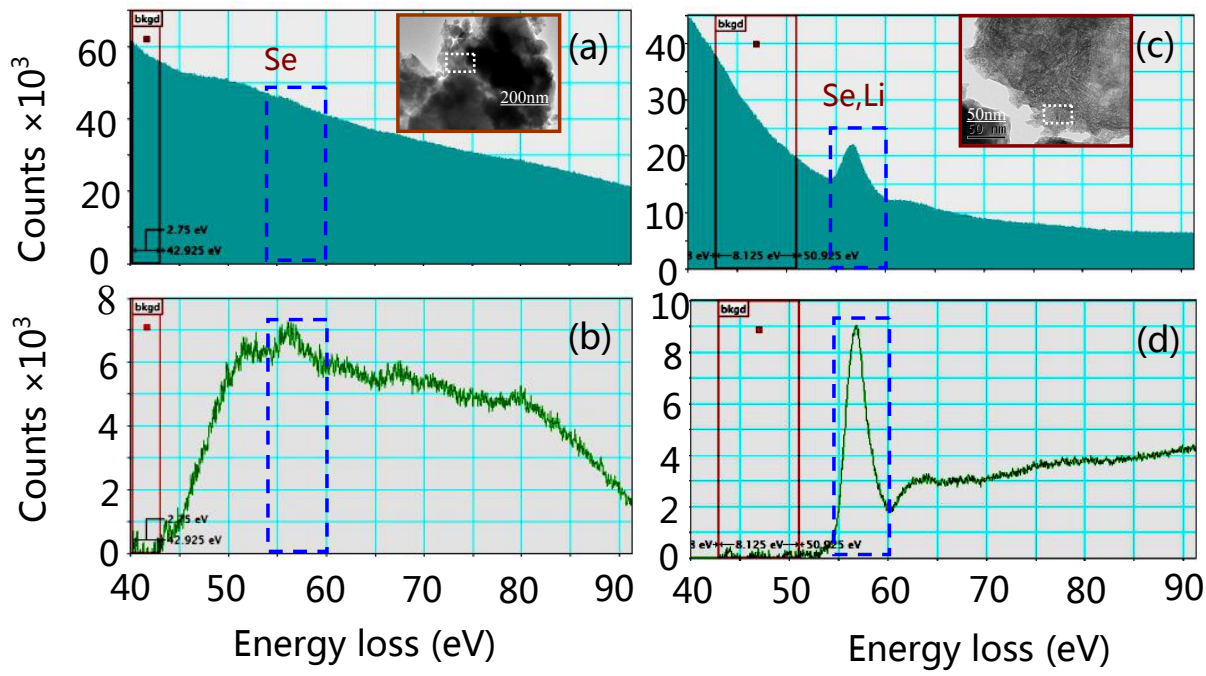

Figure 2

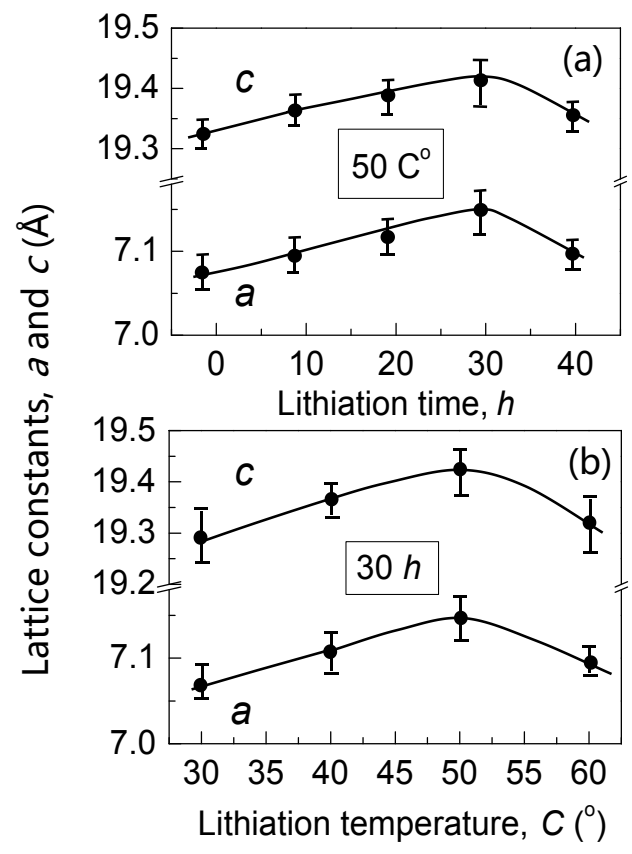

Figure 3 

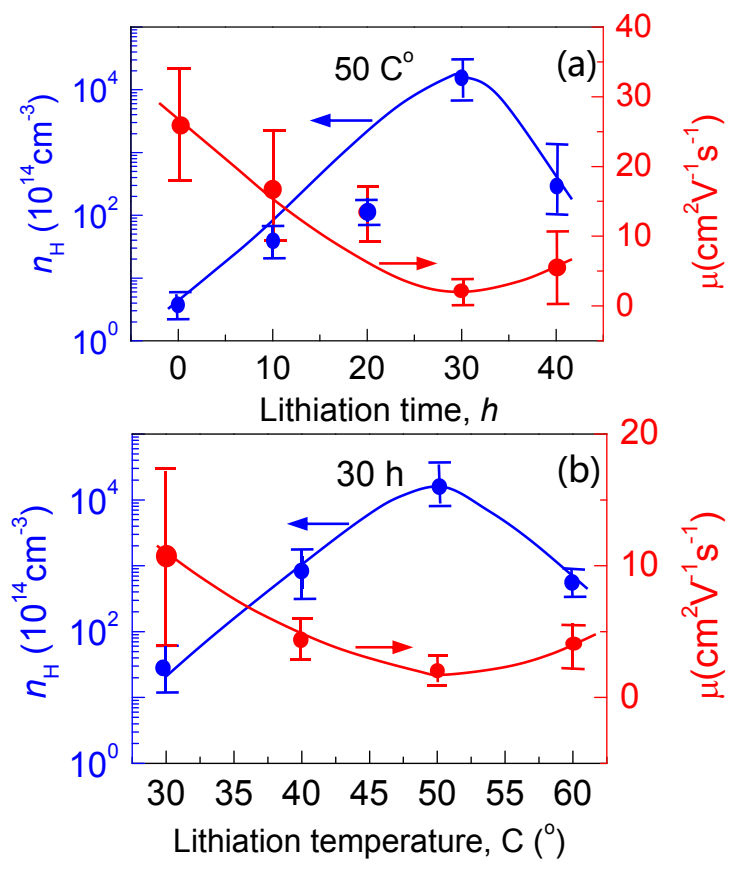

Figure 4
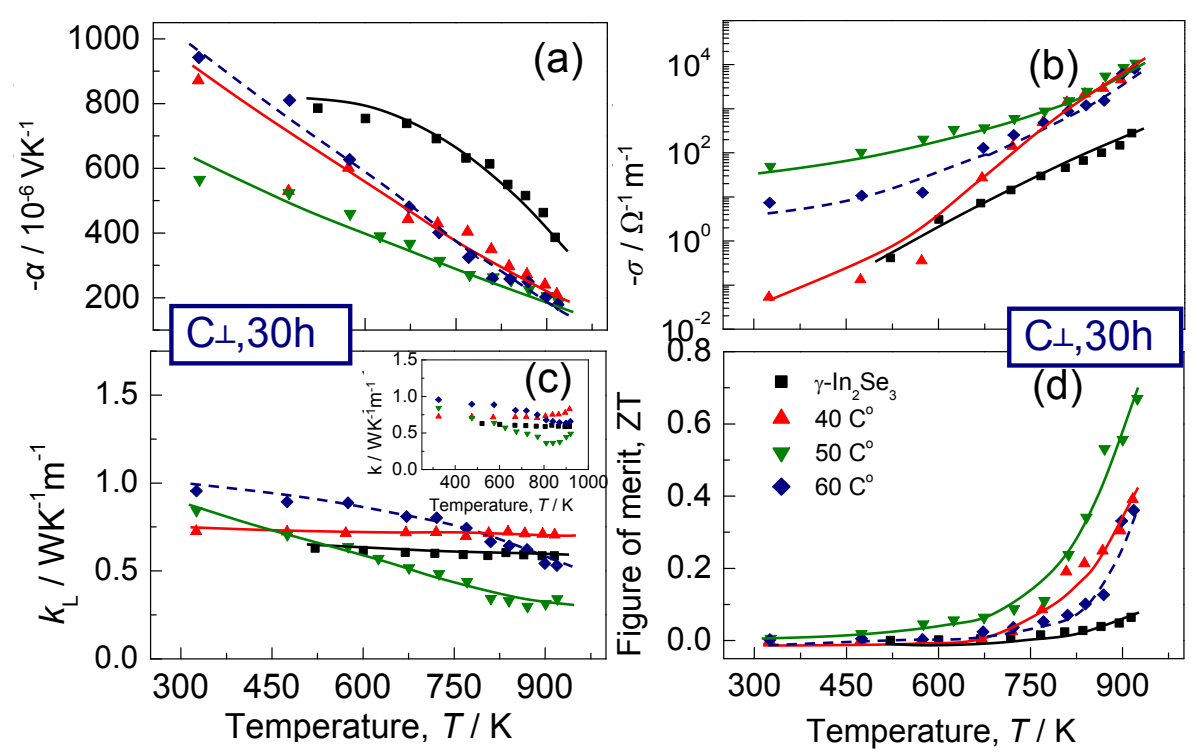

Figure 5 

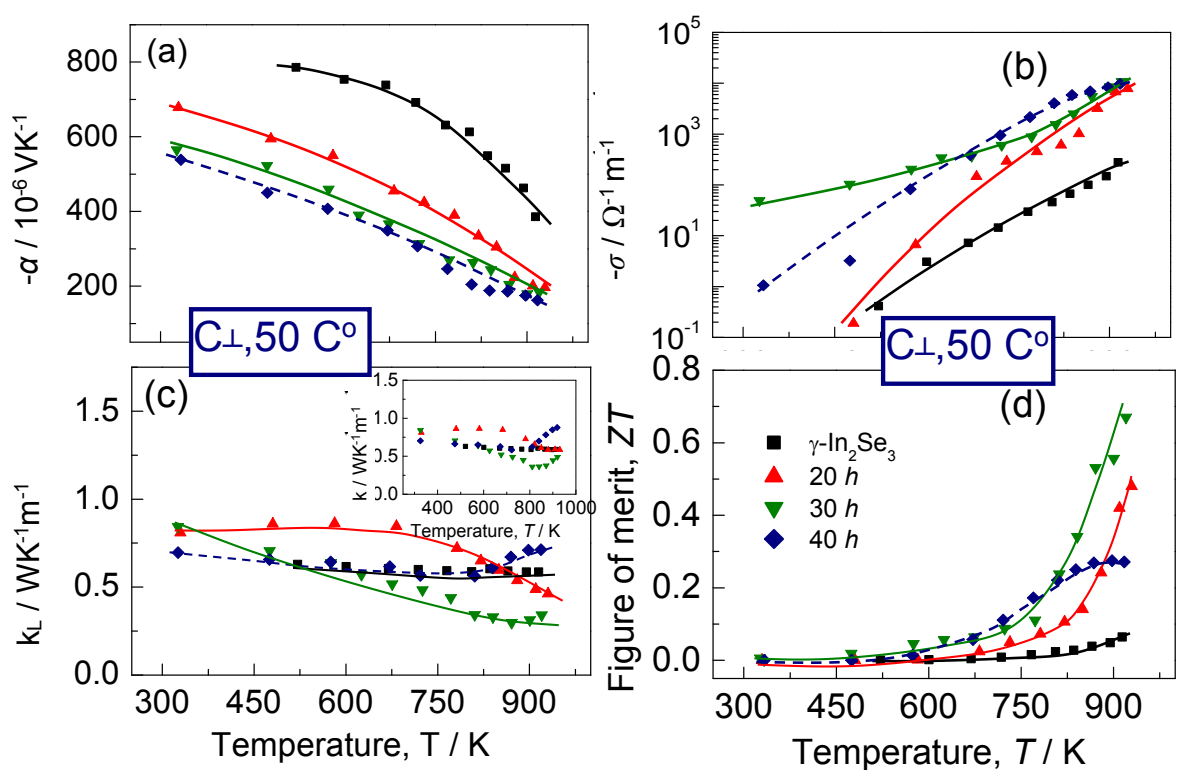

Figure 6
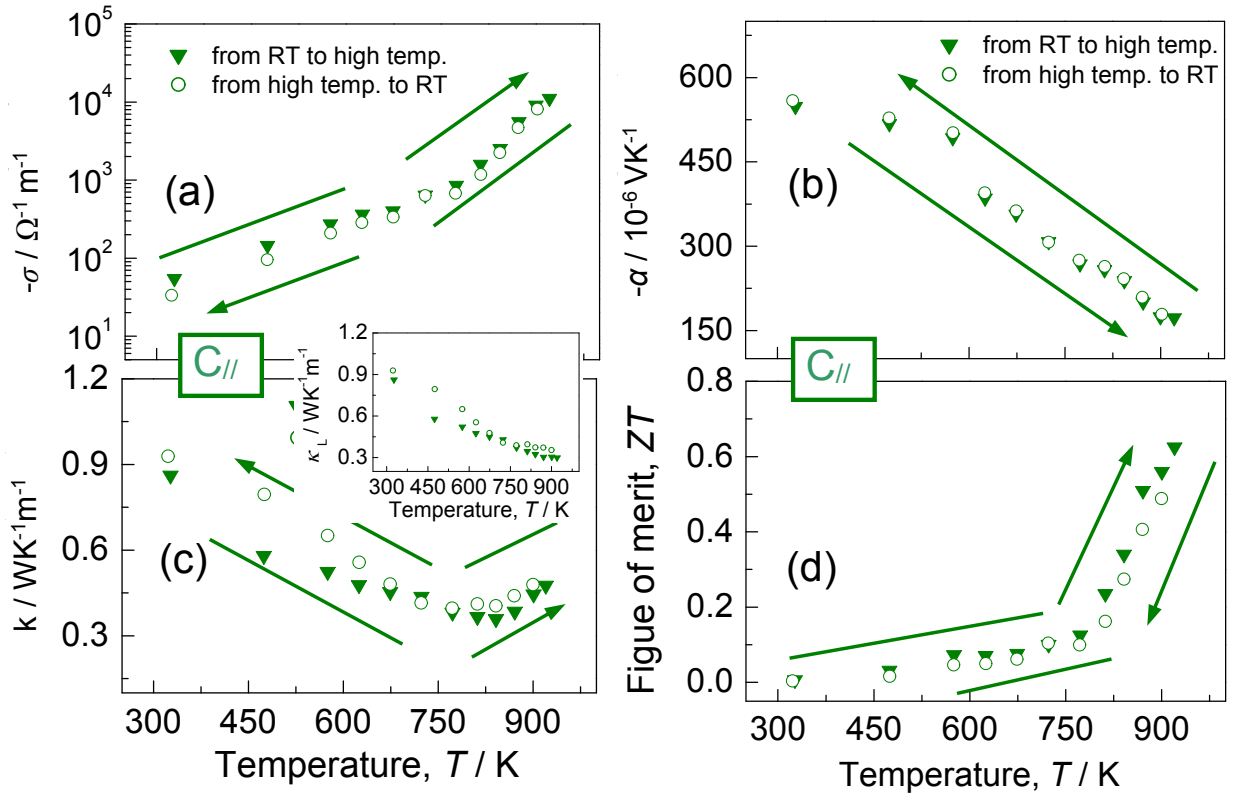

Figure 7 


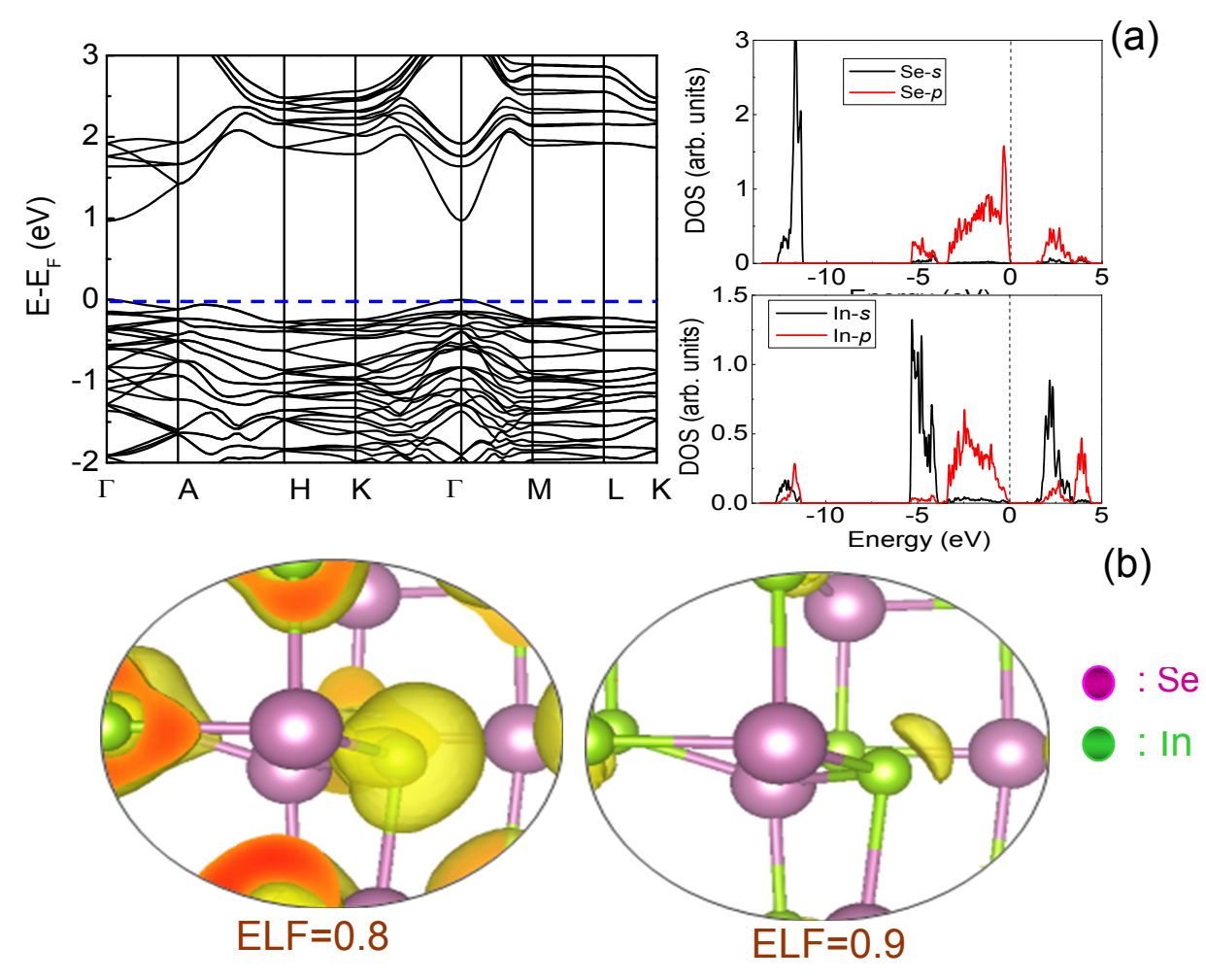

Figure 8

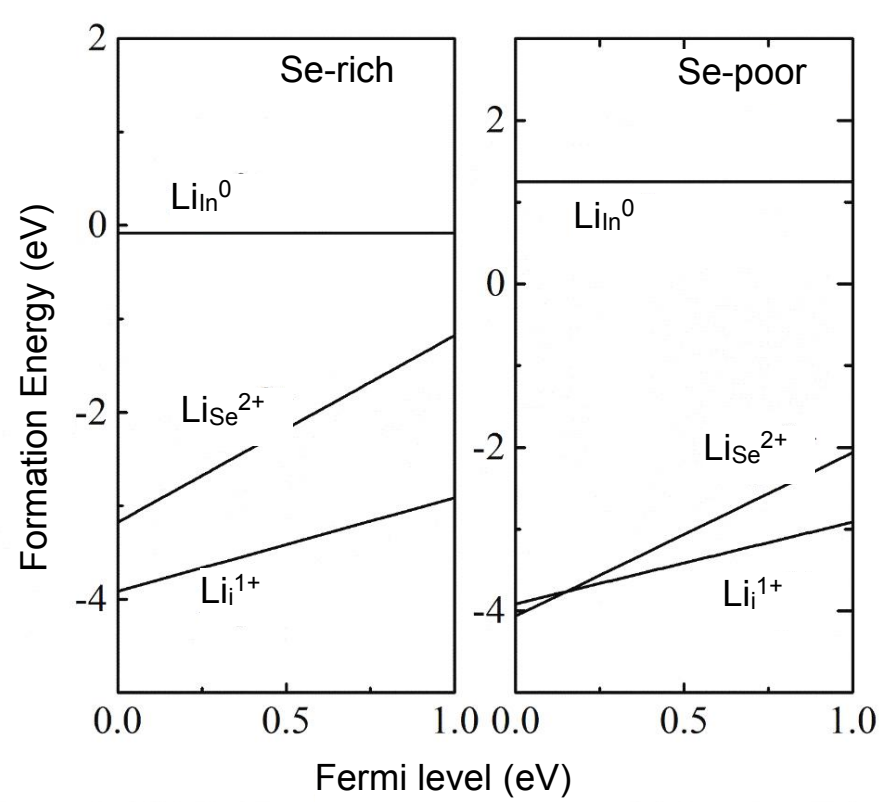

Figure 9 

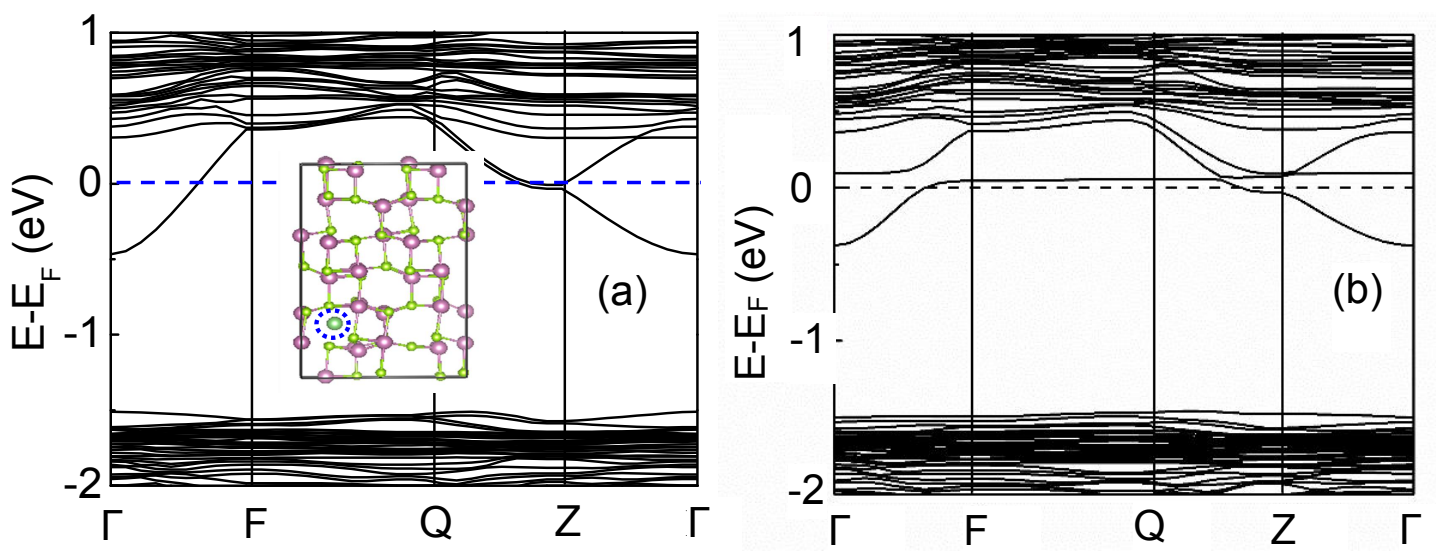

Figure 10

Table 1

\begin{tabular}{ccccc}
\hline & $\mathrm{Y}-\ln _{2} \mathrm{Se}_{3}$ & $\mathrm{Li}_{\mathrm{i}}$ & $\mathrm{Li}_{\mathrm{Se}}$ & $\mathrm{Li}_{\text {In }}$ \\
\hline$a(\AA)$ & 7.337 & 7.426 & 7.326 & 7.399 \\
$c(\AA)$ & 19.705 & 19.925 & 19.657 & 19.751 \\
\hline
\end{tabular}




\section{The table of contents entry}

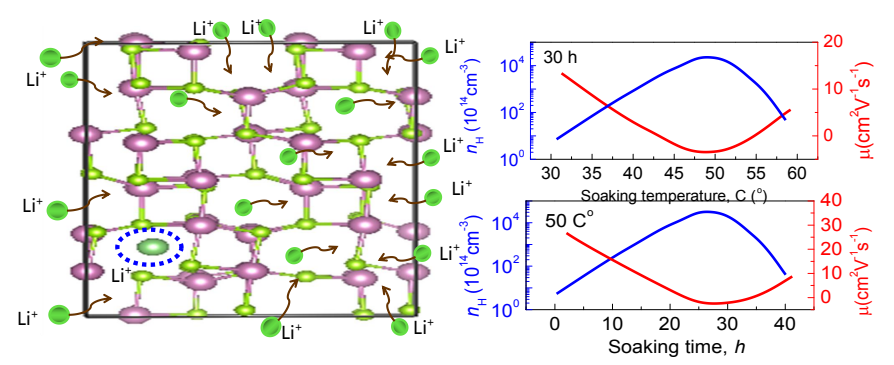

